\title{
Impacto de Aplicações de Captura e Acesso em Estudantes de Cursos de Computação
}

\section{Impact of Capture and Access Applications in Students of Computing Courses}

\author{
Taffarel Brant-Ribeiro \\ Renan Gonçalves Cattelan \\ Universidade Federal de Uberlândia, Faculdade de Computação. \\ Uberlândia, MG, Brasil. \\ tbrantr@doutorado.ufu.br, renan@ufu.br
}

\author{
Nádia Giaretta Biase \\ Universidade Federal de Uberlândia, \\ Faculdade de Matemática. \\ Uberlândia, MG, Brasil. \\ nadia@famat.ufu.br
}

\begin{abstract}
Resumo Captura e Acesso é um tema de pesquisa recorrente em Computação Ubíqua, que versa sobre o registro de conteúdo multimídia para posterior disponibilização e acesso. No âmbito acadêmico, seu uso permite a automatização de atividades educacionais, colaborando com processos de ensino e aprendizagem e criando Ambientes Educacionais Ubíquos. Nesse contexto, esta pesquisa buscou explorar o impacto de uma plataforma educacional ubíqua denominada Classroom eXperience (CX), cujo uso por turmas de cursos de graduação e pós-graduação foi acompanhado ao longo de quatro semestres letivos. Variáveis de desempenho e assiduidade foram coletadas e analisadas empregando-se técnicas estatísticas para a certificação dos dados obtidos. Também foram reunidas impressões gerais dos usuários durante o uso do sistema. Como resultado, observou-se que o uso do sistema propiciou aumento de desempenho tanto nas turmas de graduação quanto nas de pós-graduação, sendo maior nas primeiras. A assiduidade dos alunos de ambas as vertentes não sofreu mudanças expressivas entre turmas que tiveram ou não contato com a aplicação. Os estudantes informaram que prestaram mais atenção nas explicações dos professores que usaram o sistema durante as aulas, justificando que não precisaram anotar tudo o que foi escrito e puderam concentrar-se no conteúdo exposto. Além disso, declararam que a gravação das aulas não os desestimulou a frequentarem as disciplinas presencialmente, encorajando-os a estudarem mais.
\end{abstract}

Palavras-Chave: Captura e Acesso; Learning Analytics; Validação de Aplicações Educacionais; Ambientes Educacionais Ubíquos.

\begin{abstract}
Capture and Access is a recurring theme of research in Ubiquitous Computing, which comprises the recording multimedia content for later provision and access. In academic scope, its use allows the automation of educational activities, collaborating with teaching and learning processes and creating Ubiquitous Learning Environments. In this context, this study aimed to explore the impact of a ubiquitous learning platform called Classroom eXperience (CX), which usage by groups of undergraduate and graduate students was monitored over four semesters. Variables such as user performance and attendance were collected and analyzed employing statistical techniques for data certification. General impressions from students were also gathered. As a result, system usage resulted in a performance increase for both undergraduate and graduate students, being higher among the former ones. Student attendance suffered no significant changes either for those who have or have not had contact with the platform. Students reported they were able to pay more attention to explanations of instructors who used the system during classes, justifying they did not need to annotate everything written by the instructor and could concentrate on content displayed. In addition, they declared content recording did not discourage their attendance, but rather incited them to study more.
\end{abstract}

Keywords: Capture and Access; Learning Analytics; Educational Application Validation; Ubiquitous Learning Environments. 


\section{Introdução}

No início da década de 90, Mark Weiser prenunciouem seu artigo The Computer for the 21st Century - que no futuro os computadores passariam a habitar os mais corriqueiros objetos do cotidiano [28]. Argumentou que os dispositivos computacionais tornariam-se invisíveis à percepção humana - no contexto de que estariam intimamente ligados ao dia a dia - e deduziu que as tecnologias mais profundas seriam capazes de desaparecer a ponto de se tornarem indistinguíveis, entrelaçando-se por completo ao modo de vida das pessoas.

Atualmente, pouco mais de duas décadas após a publicação desse artigo, é possível perceber que as pessoas passaram a fazer uso demasiado de equipamentos tecnológicos, mantendo-se durante a maior parte do tempo quando não integralmente - conectadas à Internet [13] e em ambientes capazes de proporcionar interações entre humanos e computadores [14]. A este paradigma tecnológico de interação entre homem e máquina é atribuído o nome de Computação Ubíqua (UbiComp), cuja utilização permite conceder aos usuários a capacidade de receber o auxílio de equipamentos computacionais no exercício de suas tarefas do dia a dia.

Ao se realizar a instrumentação de espaços predeterminados - como salas de reuniões, áreas domésticas ou ambientes educacionais - com equipamentos tecnológicos da UbiComp, aborda-se uma área de pesquisa intitulada Captura e Acesso (C\&A) [25]. Esse campo versa, essencialmente, sobre o processo de se registrar o conteúdo apresentado em determinados locais e disponibilizálo posteriormente, de maneira que os usuários envolvidos sejam capazes de acessar as informações capturadas no momento em que preferirem.

No âmbito educacional, as aplicações de C\&A permitem a automatização das atividades pedagógicas, contribuindo com os processos de ensino e aprendizagem ao equipar salas de aula com dispositivos tecnológicos e criando Ambientes Educacionais Ubíquos (AEUs) [23, 31]. Ao se utilizar equipamentos de captura posicionados estrategicamente em salas instrumentadas, é possível automatizar o processo de autoria de material pedagógico, compondo acervos de arquivos multimídia e apresentando-os utilizando recursos de personalização e recomendação de conteúdo [3, 32]. Atividades nesse contexto acabam integrando ambientes virtuais e reais de aprendizagem, eliminando limites físicos das salas de aula e abordando uma área de pesquisa intitulada Aprendizagem Ubíqua (U-Learning) [1, 17].

O processo de desenvolvimento de aplicações de C\&A abrange uma gama de peculiaridades que vai desde a formalização e a implantação de arquiteturas computacionais complexas até a elaboração e execução de méto- dos para avaliar essas aplicações em ambientes reais [24, 25]. Em função disso, investigar o uso de uma aplicação de C\&A é uma atividade essencial para se obter respaldo de usuários e determinar o grau de impacto que uma arquitetura computacional ubíqua causa no ambiente educacional [23].

Nesse contexto, o presente artigo analisa o impacto de uma plataforma educacional ubíqua denominada Classroom eXperience (CX), implantada na Faculdade de Computação da Universidade Federal de Uberlândia, cuja utilização por turmas de cursos de graduação e pósgraduação foi acompanhada no decorrer de quatro semestres letivos. Utilizando dados de fontes diversificadas, como $\log s$ de acesso, desempenho, assiduidade de alunos e questionários baseados em aspectos de interatividade e utilização do sistema, foi possível avaliar o nível de satisfação de usuários que interagiram com a plataforma e mensurar se ela realmente beneficiou quem a utilizou e em qual proporção esse fenômeno aconteceu.

O restante do texto deste trabalho está estruturado da seguinte maneira: na Seção 2, abordam-se temáticas sobre Captura e Acesso, Ambientes Educacionais Ubíquos, a plataforma Classroom eXperience e vertentes de pesquisa no campo. Na Seção 3, o método de pesquisa é detalhado e os resultados obtidos são apresentados na Seção 4, junto às discussões. Na Seção 5 , são analisados trabalhos relacionados e, por fim, na Seção 6, são feitas as considerações finais do artigo.

\section{Captura e Acesso}

A área de C\&A é uma vertente de pesquisa da UbiComp que tem como objetivo auxiliar usuários durante a realização de tarefas cotidianas, registrando e produzindo fluxos multimídia por meio de recursos computacionais capazes de se adaptarem aos ambientes em que são inseridos $[16,22,25]$. Diversos trabalhos científicos têm investigado o emprego das aplicações de C\&A em contextos variados, demonstrando que sua utilização pode ser feita de maneira mais sintética - por meio de um único equipamento de captura de mídias - ou de modo mais complexo e estruturado - em infraestruturas compostas por vários dispositivos que operam em conjunto para a mesma finalidade. Em função disso, as aplicações de C\&A são capazes de abranger um amplo leque de possibilidades que permite o seu uso em diversas circunstâncias, tais como em locais de trabalho e salas de reuniões $[10,21,27,30]$, em situações do dia a dia e momentos pessoais $[2,9,15]$ e em ambientes acadêmicos onde ocorrem atividades educacionais $[1,6,8,23,29]$.

De acordo com Truong \& Hayes [25], para que uma aplicação de C\&A se mostre efetiva, ela deve seguir um 
processo padronizado de atividades com base em quatro fases sequenciais, denominadas: pré-produção, gravação ao vivo, pós-produção e acesso. Inicialmente, na etapa de pré-produção, é necessário preparar o conteúdo que será registrado numa sessão de captura. Neste momento, realiza-se a elaboração do que será versado e premedita-se o funcionamento de como a captura acontecerá. Em seguida, na gravação ao vivo, o registro dos fluxos de mídias acontece conforme inicialmente estabelecido. Tal captura pode ocorrer, dependendo do emprego da aplicação de C\&A, tanto em ambientes profissionais instrumentados quanto em circunstâncias não planejadas, por exemplo. Após a fase de gravação, entra-se na etapa de pósprodução, responsável pelo processamento dos fluxos de conteúdo que foram capturados e, por fim, na fase de acesso, em que há a apresentação dos conteúdos capturados aos usuários finais.

Embora aparentem fazer parte de um processo sequencial imutável, tais etapas não devem ser vistas apenas como passos a serem seguidos durante a construção de aplicações de C\&A. Seu real propósito diz respeito à fundamentação essencial necessária para se criar, estruturar e organizar corretamente o funcionamento de dispositivos computacionais para esse fim. Por causa disso, é possível fazer adaptações nessa estrutura, de maneira a adequá-la ao contexto no qual a aplicação será inserida e, desse modo, realizar personalizações, tais como a união das etapas de gravação e pós-produção em uma só ou, até mesmo, a criação de fases adicionais [25].

\subsection{Ambientes Educacionais Ubíquos}

Ao se instrumentar salas de aula com dispositivos computacionais ubíquos, torna-se possível empregar a UbiComp no escopo educacional, automatizando processos de ensino e aprendizagem e gerando benefícios para

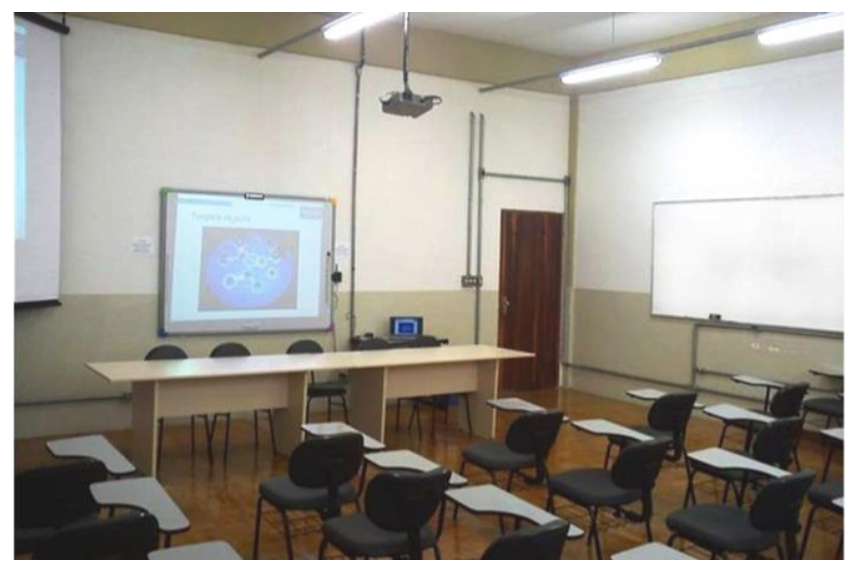

alunos e professores por meio da criação de Ambientes Educacionais Ubíquos (AEUs) $[1,17]$. Um AEU, desse modo, pode ser criado a partir da integração de componentes de C\&A, tais como microfones, câmeras e lousas digitais, de maneira a propiciar a captura automática dos conteúdos abordados em sala de aula e permitir seu acesso posterior pelos usuários.

Em função disso, o processo de gravação de mídias deve acontecer de maneira transparente para os envolvidos, permitindo que ambos interajam com as aplicações sem que haja mudanças no modo em que as aulas são conduzidas [31]. Ao final das sessões de captura, os fluxos de conteúdo devem ser sincronizados e armazenados, de maneira a possibilitar também a criação de arcabouços de conteúdo que podem ser acessados pelos usuários em circunstâncias desejadas - bastando apenas que estes possuam conectividade com a Internet.

\subsection{Classroom eXperience}

O Classroom eXperience $(\mathrm{CX})^{1}$ é uma plataforma educacional de C\&A desenvolvida com o intuito de registrar os fluxos de conteúdo apresentados em sala de aula e disponibilizá-los posteriormente para que alunos e professores possam ter acesso [3, 8]. Por meio de seu uso, é possível fazer a captura, armazenamento, acesso e extensão das mídias geradas em ambientes educacionais instrumentados e contribuir com os processos de ensino e aprendizagem de usuários que utilizam essa tecnologia no cotidiano. Para que essas atividades sejam realizadas de maneira transparente, o sistema atualmente conta com duas salas de aula equipadas com dispositivos computacionais (como lousas digitais, câmeras, microfones e projetores multimídia), localizadas na Faculdade de Computação da Universidade Federal de Uberlândia, conforme ilustrado na Figura 1.

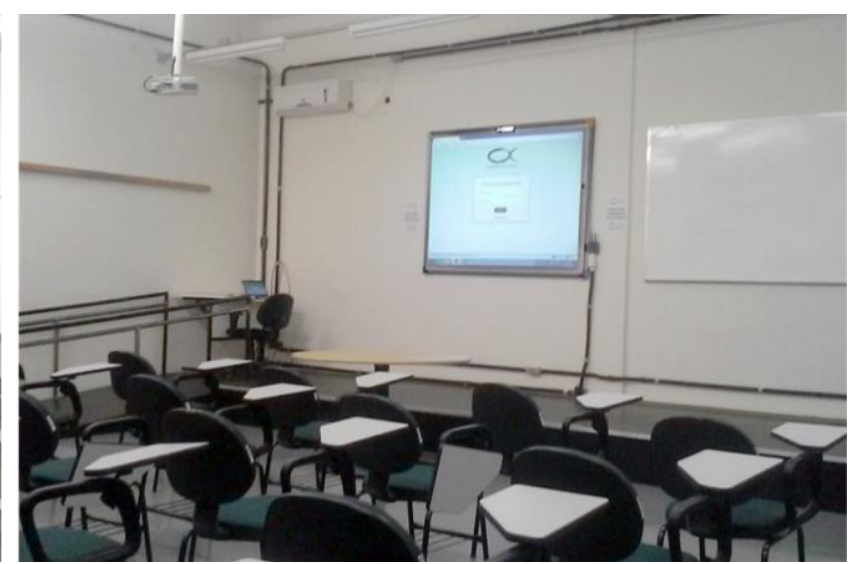

Figura 1: Salas de aula instrumentadas com lousas digitais, câmeras e projetores multimídia.

${ }^{1}$ http://cx.facom.ufu.br 
Demandando modificações mínimas na maneira com que as aulas convencionais são lecionadas, o CX emprega recursos da UbiComp para auxiliar tanto os professores enquanto realizam a captura das aulas - quanto os alunos - durante atividades de estudo e acesso ao conteúdo capturado. Para isso, o sistema conta com uma série de componentes de hardware e software especializados para realizar a gravação das atividades educacionais, fazer a sincronia automática dos fluxos de mídia concebidos e colocar à disposição o conteúdo por meio de uma interface de acesso amigável e intuitiva, cujas telas podem ser observadas nas Figuras 2 e 3.

Ao fazerem login no sistema, os usuários são direcionados para uma tela que contém um mini formulário de contexto de acesso (Figura 2). Esses dados fazem parte de um conjunto padronizado de dimensões de contexto que tem como objetivo aferir informações dos usuários em tempo de execução para proporcionar uma melhor experiência enquanto realizam acessos e interagem com o sistema [3]. Dessa maneira, as dimensões de contexto trabalham em conjunto para fornecer benefícios aos usuários, tais como personalizações, recomendações e restrições de mídias referentes ao conteúdo capturado. Atual-

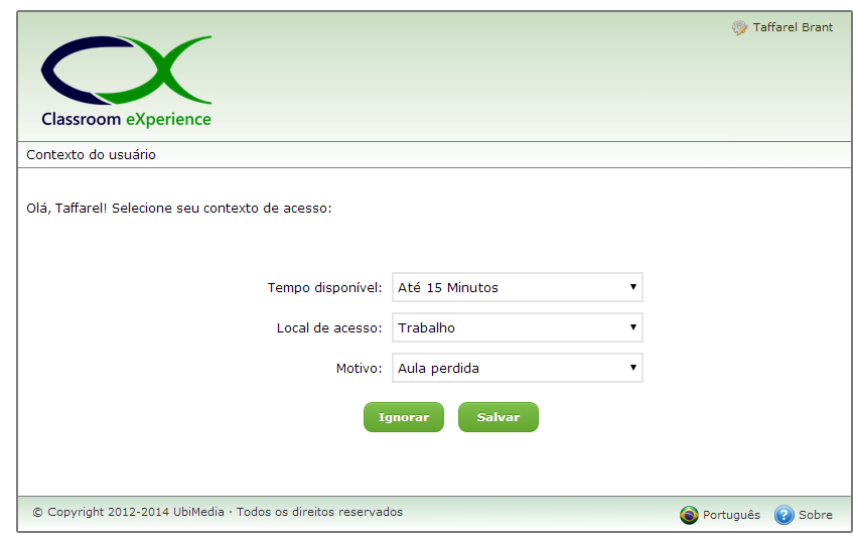

Figura 2: Página de seleção de contexto da interface Web do CX.

(a)

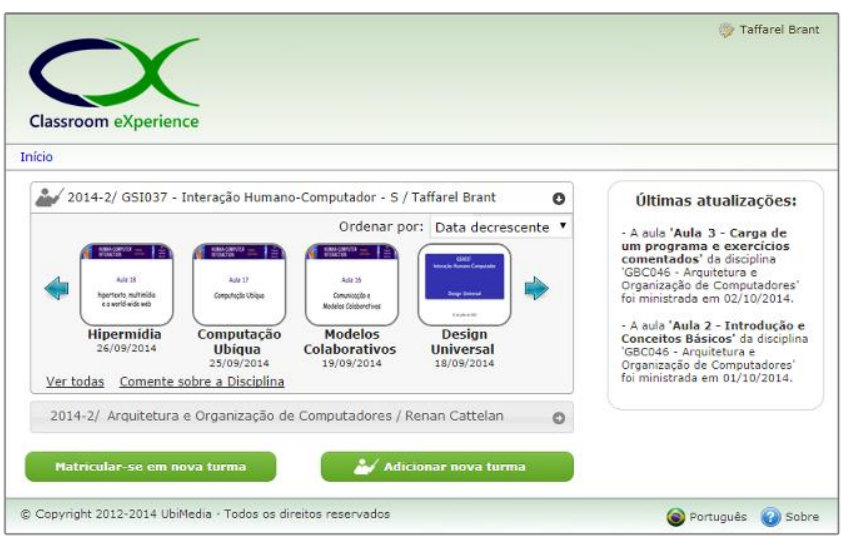

mente, o CX utiliza sete dimensões de contexto: a) tipo de dispositivo, b) velocidade de conexão, c) resolução da tela, d) data e hora de acesso, e) tempo disponível, f) local de origem do acesso e g) motivo do usuário acessar o sistema. Dessas, as quatro primeiras são aferidas automaticamente pelo sistema, enquanto as três últimas precisam ser informadas pelo usuário por meio do mini formulário de contexto presente na Figura 2.

A definição das sete dimensões de contexto supracitadas seguiu a proposta de Truong et al. [26], que estabeleceu um conjunto de questões a serem consideradas para o desenvolvimento de módulos contextuais para aplicações de C\&A. Como foge do escopo desse artigo discutir com maiores detalhes o mapeamento das dimensões de contexto e sua utilização para personalização do acesso ao conteúdo capturado, mais informações podem ser encontradas em Araújo et al. [3] e Ferreira et al. [8].

Após informarem as dimensões de contexto, os usuários são direcionados para a página principal do sistema (Figura 3(a)), onde é possível - para um professor - adicionar uma nova turma e - para ambos os usuários realizar matrículas nas turmas já cadastradas no sistema. Além disso, esta página também exibe as últimas atualizações que aconteceram no $\mathrm{CX}$, tais como aulas que foram capturadas recentemente e avaliações registradas pelos professores - como provas, trabalhos, exercícios e seminários. De modo a melhorar a organização desses dados, eles são exibidos utilizando-se filtros temporais e de disciplinas vinculadas aos usuários, de maneira que apenas alunos matriculados em turmas nas quais essas atualizações acontecem são capazes de enxergar essas informações na página principal.

Ao selecionarem uma aula específica, os usuários devem escolher em qual formato de apresentação o conteúdo capturado será exibido. No $\mathrm{CX}$, atualmente há três tipos de formato de apresentação: somente slides, somente vídeo e completo. Caso selecione a primeira opção, o usuário será direcionado para uma página contendo os slides utilizados pelo professor durante uma sessão de

(b)



Figura 3: Páginas principal e de aula capturada da interface Web do CX. 
captura, já com as anotações feitas nessas mídias. A segunda opção apresentará apenas o vídeo de uma aula capturada pelo sistema e a terceira exibirá ambos os fluxos de mídia, conforme a Figura 3(b).

\section{Método de Pesquisa}

Para esta pesquisa, desenvolveu-se um módulo para registrar os logs dos usuários que tiveram contato com o CX. Tais $\log s$ armazenaram informações relativas ao contexto em que os usuários se encontravam ao acessar o sistema durante os quatro semestres letivos compreendidos pela pesquisa. Ao final de cada período, aplicou-se questionários para discentes com o intuito de investigar suas impressões com relação ao sistema. Tais questionários foram compostos por uma lista de 18 afirmativas acompanhadas de Escalas Likert de 5 pontos, seguidas de duas questões nas quais os alunos deveriam informar os motivos que mais os levaram a utilizar o CX e suas críticas e sugestões sobre a aplicação. Para legitimar as respostas obtidas, fez-se o uso de técnicas de legitimação de respostas utilizando tanto a negação de alternativas - de modo que as informações-chave do questionário tiveram suas ideias presentes em mais de uma pergunta, sendo apresentadas de maneira aparentemente oposta [12] quanto limites inferiores temporais - pois um período mínimo de tempo era necessário para se ler, compreender e responder as questões apresentadas [18].

Também coletaram-se dados relativos à assiduidade e ao rendimento de alunos que frequentaram disciplinas nas quais o CX foi empregado no decorrer dos semestres analisados. Com relação à presença em sala de aula, gráficos de frequência foram gerados, ilustrando os diferentes fluxos de assiduidade que ocorreram entre os discentes de cursos de graduação e pós-graduação. Sobre a frequência de acesso ao sistema, geraram-se gráficos que ilustraram a maneira que o sistema foi utilizado durante os semestres - com base nos motivos que levaram os usuários a visitarem-no - e realizaram-se discussões de modo a enriquecer a compreensão dos resultados obtidos.

Finalmente, para investigar o desempenho dos alunos, suas notas foram analisadas para averiguar se o uso do CX trouxe aumento de rendimento entre as turmas sob observação. A princípio, calculou-se a média e o desvio padrão das notas das turmas, organizando os resultados com relação ao nível frequentado pelos discentes (graduação ou pós-graduação) e emprego do sistema durante os semestres (parcial, ausente ou presente). A esses dados, foram aplicados os testes de Shapiro-Wilk (SW) e Levene para, respectivamente, investigar se os resíduos das amostras seguiam uma distribuição normal e se havia homogeneidade de variâncias entre as turmas que cursaram as mesmas disciplinas. Em seguida, aplicou-se o teste $t$ de Student para averiguar a existência de diferenças expressivas entre as médias das turmas observadas e, por fim, os resultados obtidos foram discutidos e comparados aos de trabalhos relacionados, com o intuito de evidenciar os ganhos obtidos e os pontos a serem melhorados por meio de trabalhos futuros.

Tendo em mente que a população desta pesquisa foi constituída por alunos que frequentam cursos de graduação e pós-graduação, determinadas subpopulações (ou estratos) foram distinguidas entre as unidades, garantindo à população um caráter heterogêneo. Para assegurar que os elementos das amostras admitissem níveis similares durante as análises, optou-se por dividi-los em grupos. Desse modo, isolaram-se alunos que frequentaram a graduação daqueles que cursaram a pós-graduação. Ainda, devido as disciplinas analisadas possuírem altos níveis de tecnicidade, esta pesquisa pressupôs que os alunos de graduação observados não tiveram contato anterior com os conteúdos abordados nas disciplinas.

Em função dessa divisão da população em aglomerados e julgamento integral dos dados coletados em cada um dos grupos, empregou-se o método de amostragem estratificada. Dessa maneira, foi possível compreender o efeito do CX entre grupos de usuários com diferentes níveis de instrução, o que permitiu uma análise realista das informações obtidas durante os semestres letivos.

\section{Resultados e Discussões}

Durante quatro semestres letivos, observaram-se 13 turmas que cursaram 3 disciplinas distintas, totalizando 316 alunos envolvidos na pesquisa. Deles, 214 tiveram contato com o sistema e 102 fizeram parte de turmas de controle, nas quais a aplicação não foi utilizada. Dados foram coletados de maneira contínua entre as disciplinas, sendo que o fator sob investigação (o uso do $\mathrm{CX}$ ) recebeu diferentes tratamentos entre elas. Desse modo, a utilização da plataforma foi especificada com base em seu emprego durante os semestres, classificando-se como uso integral, uso parcial e ausência de uso do CX nas turmas que tiveram seus elementos observados.

Dos 214 alunos que tiveram contato com o sistema, 114 o utilizaram parcialmente (apenas durante os segundos bimestres dos semestres avaliados) e 100 dispuseram integralmente do CX no decorrer dos períodos letivos. Para que testes de comparação pudessem ser realizados, os 102 discentes que não tiveram contato com o sistema cursaram as mesmas disciplinas que os demais. Dessa maneira, os três tratamentos foram investigados e analisados entre si, de modo a compreender melhor o uso do sistema entre os alunos. 


\subsection{Desempenho}

Notas dos discentes foram utilizadas para averiguar se a utilização do CX trouxe, de fato, aumento de desempenho entre as turmas sob análise. Para isso, inicialmente as amostras coletadas foram submetidas ao teste de SW para verificar se os resíduos da variável observada seguiam uma distribuição normal. Em seguida, aplicou-se o teste de Levene entre amostras de turmas diferentes que cursaram as mesmas disciplinas para averiguar se possuíam homocedasticidade - ou seja, se havia homogeneidade de variâncias entre elas. Por fim, o teste $t$ de Student foi utilizado para se comprovar a existência de diferenças significativas entre as médias das turmas.

Devido à utilização da amostragem estratificada, turmas de graduação e pós-graduação foram avaliadas de maneira separada. Além disso, para organizar os resultados, optou-se por agrupar as análises das amostras que tiveram contato integral e ausência de uso do CX, separando-as das avaliações realizadas nas turmas que utilizaram o sistema de maneira parcial. Como resultado, na Tabela 1 é possível observar o desempenho de oito turmas (seis de graduação e duas de pós-graduação) que tiveram o CX presente ou ausente no decorrer dos semestres letivos.

Todas as amostras analisadas apresentaram normalidade de resíduos e homogeneidade de variâncias entre as disciplinas. Embora as médias das turmas que tiveram contato integral com o CX tenham sido aparentemente maiores, houve aumento de desempenho significativo apenas entre os alunos de graduação que cursaram as disciplinas B e C. As médias das turmas que cursaram a disciplina $\mathrm{A}$, tanto na graduação quanto na pós- graduação, não apresentaram diferenças expressivas. Entretanto, na pós-graduação, houve uma menor dispersão das notas em torno da média da turma, o que permite compreender que os alunos passaram a estudar o conteúdo a partir de uma fonte em comum e isso garantiu um maior nivelamento entre as notas obtidas pelos alunos.

Com o intuito de melhorar o entendimento dos dados apresentados na Tabela 1, construíram-se Boxplots das turmas observadas (Figura 4). No diagrama gerado, o eixo horizontal foi responsável pela representação das amostras e o vertical ilustrou a variável sob análise (desempenho dos alunos). As linhas que dividem as caixas ao meio são as medianas amostrais e as partes coloridas acima e abaixo das medianas são limitadas por quartis superiores e inferiores. Essas três marcações fazem a separação das amostras em quatro partes, representando, cada uma, 1/4 dos dados observados. Após os quartis, há linhas que seguem até barras horizontais (chamadas fios de bigode), que ilustram os valores $25 \%$ maiores e menores da amostra. Por isso, a caixa limitada pelos quartis representa $50 \%$ das observações, sendo as que se encontram mais próximas à mediana.

Apesar das turmas que utilizaram o CX terem obtido médias maiores que as de seus pares, as amostras 1 e 2 apresentaram uma diferença irrisória entre suas medianas. Além disso, abaixo dos quartis da primeira turma, há duas observações afastadas das demais, sendo classificadas como outliers. Tais valores também são visíveis em outras amostras e representam a variabilidade inerente à população estudada. Tendo em vista que há circunstâncias em que os outliers ocorrem de maneira ocasional, mostra-se necessário removê-los para que não haja interpretações equivocadas. Nesta pesquisa, no entanto,

Tabela 1: Desempenho de turmas de graduação e pós-graduação quanto ao uso integral do Classroom eXperience no semestre letivo.

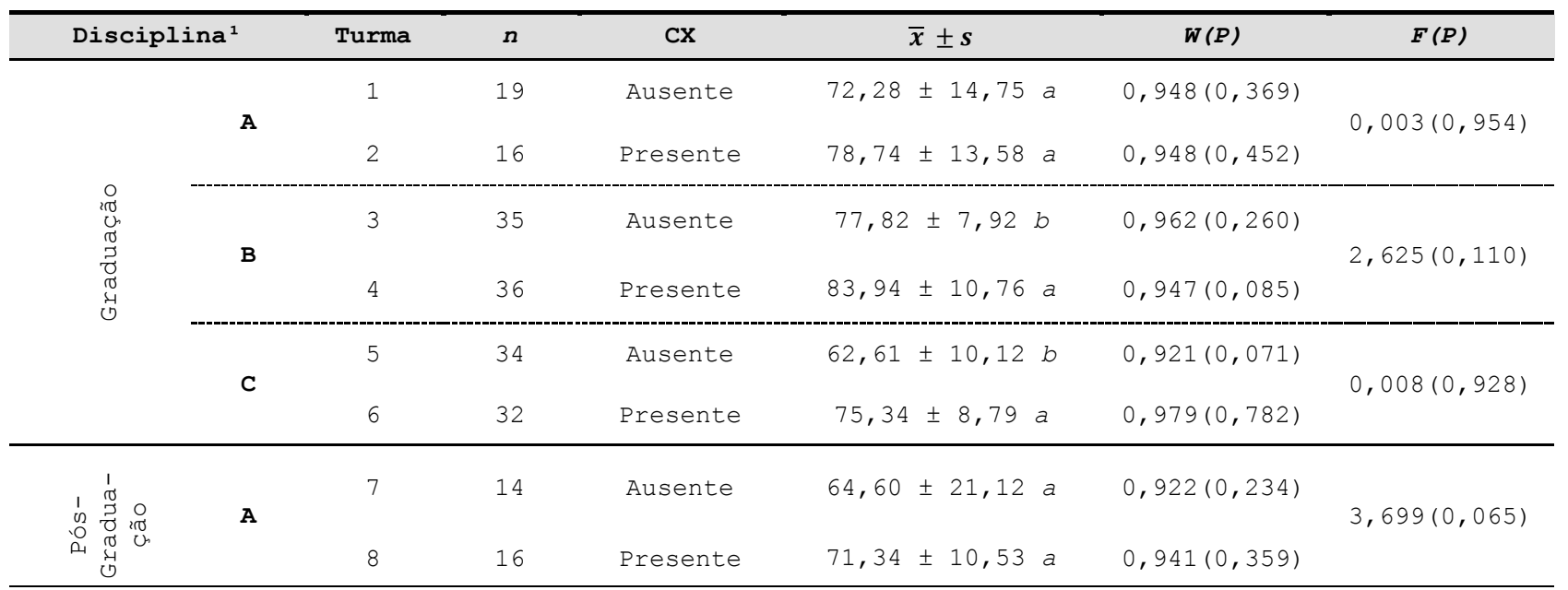

1 Médias de turmas seguidas por letras distintas em cada disciplina diferem-se entre si pelo teste $t$ de Student para amostras independentes a 0,05 de significância; $n$ : Tamanho da amostra; CX: Classroom eXperience; $\bar{x} \pm s$ : Média e desvio padrão; $W$ : Estatística do teste de Shapiro-Wilk; $F$ : Estatística do teste de Levene; $(P)$ : Probabilidades maiores que 0,05 indicam resíduos com distribuição normal e variâncias homogêneas para os testes de Shapiro-Wilk e Levene, respectivamente. 




Figura 4: Boxplots das turmas analisadas na Tabela 1.

como os dados representam observações reais e a variação das notas é algo natural das amostras, optou-se por mantê-los na análise. Na sétima amostra, os fios de bigode comprovam o tamanho desproporcional do seu desvio padrão (visto na Tabela 1) e a considerável redução dessa medida na amostra 8 . Todavia, a redução do desvio padrão e aumento da média na oitava amostra não foram expressivos o suficiente para que houvesse diferença entre as notas da pós-graduação.

Também avaliou-se o desempenho de alunos que utilizaram o CX apenas durante a segunda metade dos se- mestres letivos. O teste de SW foi aplicado a esses dados e todas as amostras apresentaram resíduos com distribuição normal. Por se tratarem de cinco turmas que tiveram os mesmos elementos observados duas vezes, realizou-se o cálculo da diferença entre as notas obtidas nos $1^{\circ}$ e $2^{\circ}$ bimestres e aplicou-se o teste $t$ de Student às diferenças resultantes (Tabela 2). Todas as turmas de graduação apresentaram aumentos significativos em seus desempenhos, mesmo utilizando o sistema parcialmente durante o semestre. Na pós-graduação, enquanto os alunos que frequentaram a disciplina $\mathrm{B}$ obtiveram aumentos expressivos nas notas, na turma $\mathrm{A}$ não houve diferença entre os bimestres. Com exceção da turma de graduação que cursou a disciplina A (na qual a média e o desvio padrão elevaram-se) todas as demais amostras apresentaram aumento em suas médias e decréscimos nos desvios padrões. Esses resultados fortalecem a premissa de que o uso do sistema nos $2^{\text {os }}$ bimestres gerou uma elevação e maior nivelamento das notas obtidas pelos alunos, conforme demonstrado pelos Boxplots da Figura 5.

A maioria das amostras de $2^{\circ}$ bimestre (nos quais o CX foi empregado) apresentou observações com o máximo de rendimento possível entre alunos (50 pontos), junto a aumentos em suas medianas e quartis inferiores. A turma de pós-graduação que cursou a disciplina $\mathrm{A}$ também obteve elevação nas médias e redução do desvio padrão, todavia, tais diferenças não se mostraram expressivas, pois a alta variabilidade das notas permaneceu no $2^{\circ}$ bimestre, conforme ilustrado por seus fios de bigode.

Tabela 2: Desempenho de turmas de graduação e pós-graduação quanto à utilização parcial do Classroom eXperience durante os dois bimestres do semestre letivo.

\begin{tabular}{|c|c|c|c|c|c|c|c|}
\hline Disc & & $n$ & Bimestre & $\mathrm{CX}$ & $\bar{x} \pm s$ & $\bar{d} \pm s_{d}$ & $F(P)$ \\
\hline \multirow{3}{*}{$\begin{array}{c}0 \\
0 \\
0 \\
0 \\
0 \\
D \\
0 \\
\pi \\
4 \\
0\end{array}$} & A & 21 & $\begin{array}{l}1^{\circ} \\
2^{\circ}\end{array}$ & $\begin{array}{l}\text { Ausente } \\
\text { Presente }\end{array}$ & $\begin{array}{l}25,64 \pm 7,27 b \\
34,38 \pm 7,79 a\end{array}$ & $8,74 \pm 10,08$ & $0,941(0,223)$ \\
\hline & B & 28 & $\begin{array}{l}1^{\circ} \\
2^{\circ}\end{array}$ & $\begin{array}{l}\text { Ausente } \\
\text { Presente }\end{array}$ & $\begin{array}{l}35,93 \pm 6,68 b \\
40,93 \pm 5,17 a\end{array}$ & $5,00 \pm 7,57$ & $0,949(0,189)$ \\
\hline & $\mathrm{C}$ & 31 & $\begin{array}{l}1^{\circ} \\
2^{\circ}\end{array}$ & $\begin{array}{l}\text { Ausente } \\
\text { Presente }\end{array}$ & $\begin{array}{l}37,03 \pm 11,14 b \\
42,51 \pm 7,04 a\end{array}$ & $5,48 \pm 9,77$ & $0,980(0,822)$ \\
\hline \multirow{2}{*}{$\begin{array}{c}0 \\
0 \\
0 \\
0 \\
\pi \\
? \\
0 \\
0 \\
0 \\
4 \\
0 \\
1 \\
0 \\
0 \\
0\end{array}$} & A & 17 & $\begin{array}{l}1^{\circ} \\
2^{\circ}\end{array}$ & $\begin{array}{l}\text { Ausente } \\
\text { Presente }\end{array}$ & $\begin{array}{l}30,15 \pm 11,82 a \\
34,26 \pm 9,27 a\end{array}$ & $4,11 \pm 8,26$ & $0,919(0,141)$ \\
\hline & B & 17 & $\begin{array}{l}1^{\circ} \\
2^{\circ}\end{array}$ & $\begin{array}{l}\text { Ausente } \\
\text { Presente }\end{array}$ & $\begin{array}{l}45,00 \pm 3,16 \mathrm{~b} \\
47,65 \pm 2,57 \mathrm{a}\end{array}$ & $2,65 \pm 2,55$ & $0,963(0,690)$ \\
\hline
\end{tabular}

\footnotetext{
${ }^{1}$ Médias bimestrais seguidas por letras distintas em cada disciplina/turma diferem-se entre si pelo teste $t$ de Student uniamostral a 0,05 de significância; $n$ : Tamanho da amostra; CX: Classroom eXperience; $\bar{x} \pm s$ : Média e desvio padrão; $\bar{d} \pm s_{d}$ : Diferença média e desvio padrão da diferença; $W$ : Estatística do teste de Shapiro-Wilk; $(P)$ : Probabilidades maiores que 0,05 indicam resíduos com distribuição normal para o teste de Shapiro-Wilk.
} 


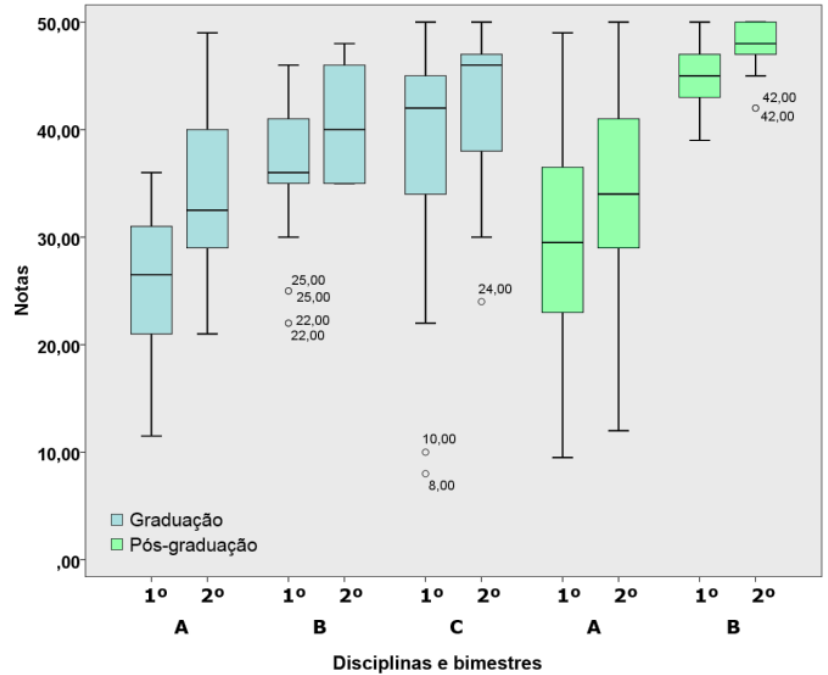

Figura 5: Boxplots das turmas analisadas na Tabela 2.

Sintetizando, tanto entre amostras em que o uso do CX foi integral quanto naquelas que utilizaram parcialmente o sistema, turmas de graduação obtiveram maiores taxas de aumento de desempenho. Dentre as quatro turmas que tiveram contato com o CX durante todo o semestre, três eram compostas por alunos de graduação e duas dessas apresentaram elevações significativas entre as notas dos alunos, enquanto na pós-graduação não houve qualquer diferença. Entre as amostras que utilizaram parcialmente o CX, todas as turmas de graduação tiveram aumentos expressivos em suas médias, ao passo que na pós-graduação apenas metade apresentou diferença entre os bimestres.

\subsection{Assiduidade}

Dos 316 alunos observados no decorrer da pesquisa, 214 tiveram contato integral ou parcial com o CX. Destes, 198 registraram-se no sistema para visualizar as aulas capturadas, resultando em $92,5 \%$ de usuários cadastrados entre os alunos cujas disciplinas foram observadas durante os semestres letivos. Para melhor compreender a assiduidade desses discentes, optou-se por analisar a presença diária dos alunos e suas frequências de acesso ao sistema. Desse modo, foi possível investigar se o emprego da tecnologia educacional ocasionou algum declínio na presença dos alunos em sala de aula.

A Figura 6 apresenta um gráfico de linhas com o fluxo de assiduidade semanal das três turmas de graduação que cursaram a disciplina A. Cores distintas foram utilizadas para classificá-las de acordo com a utilização integral, parcial ou ausente do CX em seus cotidianos. Tomando por base que os semestres letivos possuíram em média vinte semanas de duração, foi possível compreender os diferentes níveis de presença que os discentes tiveram no decorrer dos períodos observados.

A frequência percentual das presenças (de $0 \%$ a $100 \%$ ) foi representada no eixo vertical, enquanto o horizontal ilustrou as vinte semanas que foram analisadas. Ao início dos três semestres letivos houve cerca de 50\% de inassiduidade, algo já esperado devido ao comportamento dos discentes nas primeiras semanas. A partir da terceira semana, observou-se que a turma que não teve contato com o sistema (CX Ausente) começou a apresentar variações constantes e abruptas na assiduidade, sendo possível observar picos e sopés no decorrer de todo o semestre. $\mathrm{O}$

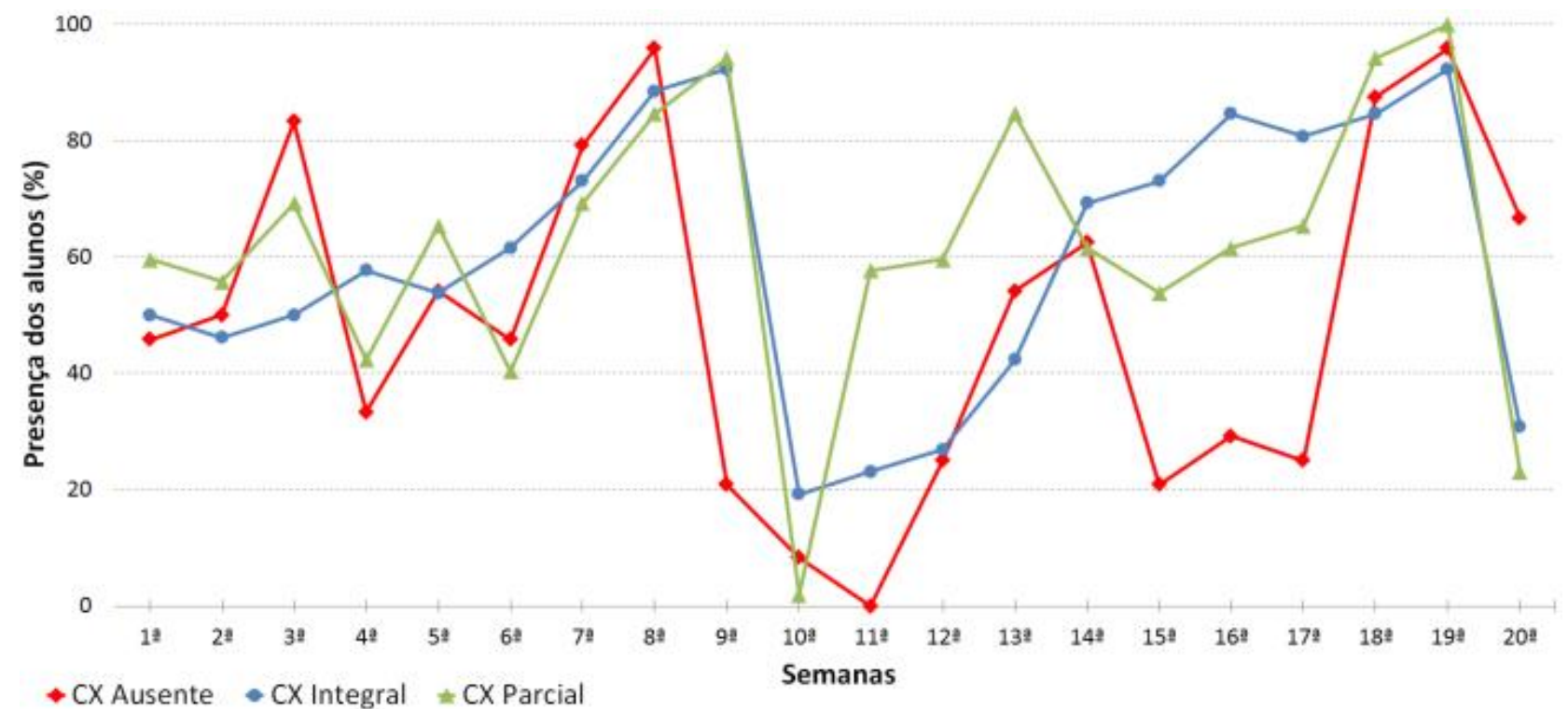

Figura 6: Frequência em turmas de graduação que cursaram a disciplina A. 
primeiro ápice desta turma (na oitava semana) aconteceu em razão da avaliação bimestral, algo que se repetiu com a mesma intensidade quando as provas do segundo bimestre se aproximaram (na décima nona semana).

A assiduidade da turma que utilizou o sistema durante todo o semestre (CX Integral) cresceu gradativamente até as semanas de provas de ambos os bimestres (nona e décima nona semanas, respectivamente). Logo após as avaliações, houve uma queda de presença perceptível em todas as turmas - um fenômeno justificável por este período normalmente compreender atividades como correções de provas e disponibilização de notas, algo que leva os alunos a faltarem mais. Após a alta taxa de faltas que sucedeu o período inicial de avaliações, a turma que não utilizou o CX apresentou um crescimento veloz em sua assiduidade, que novamente caiu e se ergueu em seguida. Os alunos que tiveram contato com o sistema por todo o semestre passaram por um processo mais gradativo de recuperação da frequência e mantiveram essa progressão até a avaliação final. A turma que teve contato parcial com o CX fez seu uso apenas no segundo bimestre, por isso percebe-se que os picos de assiduidade após a primeira prova registraram níveis maiores de presença e uma média mais estável, se comparada aos saltos observados no primeiro bimestre.

Também analisaram-se as presenças de turmas de pós-graduação no decorrer dos semestres letivos. $\mathrm{Na}$ Figura 7, a frequência percentual da assiduidade entre alunos de mestrado e doutorado que cursaram a disciplina A foi visivelmente maior que a de turmas de graduação, mantendo-se acima de $80 \%$ na maior parte das semanas observadas. Percebeu-se que entre a oitava e nona sema- nas houve picos de acesso que se repetiram ao final do semestre, representando os dias em que houve avaliações. Além disso, as quedas de presença que sucederam épocas de provas foram menores que as de turmas de graduação e em pouco tempo os níveis de assiduidade elevaram-se novamente, mantendo-se acima de $90 \%$ em alguns casos. As demais turmas de graduação e pós-graduação que frequentaram as disciplinas $\mathrm{B}$ e C também foram analisadas durante os semestres letivos e apresentaram frequências de presença similares às que cursaram $\mathrm{A}$.

No decorrer de quatro semestres, 2103 acessos foram realizados ao sistema, sendo 1696 efetuados por alunos matriculados nas disciplinas e 407 feitos por professores. Dentre as treze turmas avaliadas, quatro utilizaram o sistema integralmente e cinco fizeram seu uso apenas durante o segundo bimestre, totalizando nove turmas que tiveram contato com o CX. A Figura 8 apresenta a quantidade de acessos que as turmas que frequentaram a disciplina A realizaram ao sistema durante seus respectivos períodos letivos.

As turmas de graduação apresentaram taxas de acesso ao sistema maiores que as de pós-graduação em todos os semestres analisados. Entre alunos de mestrado e doutorado, percebeu-se que o CX não foi utilizado de maneira contínua, sendo acessado em poucas circunstâncias e por uma pequena quantidade de usuários. Isso se explica devido aos discentes de pós-graduação já possuírem seus próprios métodos de estudo, utilizando, por exemplo, bibliotecas físicas e digitais com maior frequência. A inserção de uma nova tecnologia, portanto, acaba se configurando apenas como mais uma opção, tendo sua importância e conveniência de uso diluída.

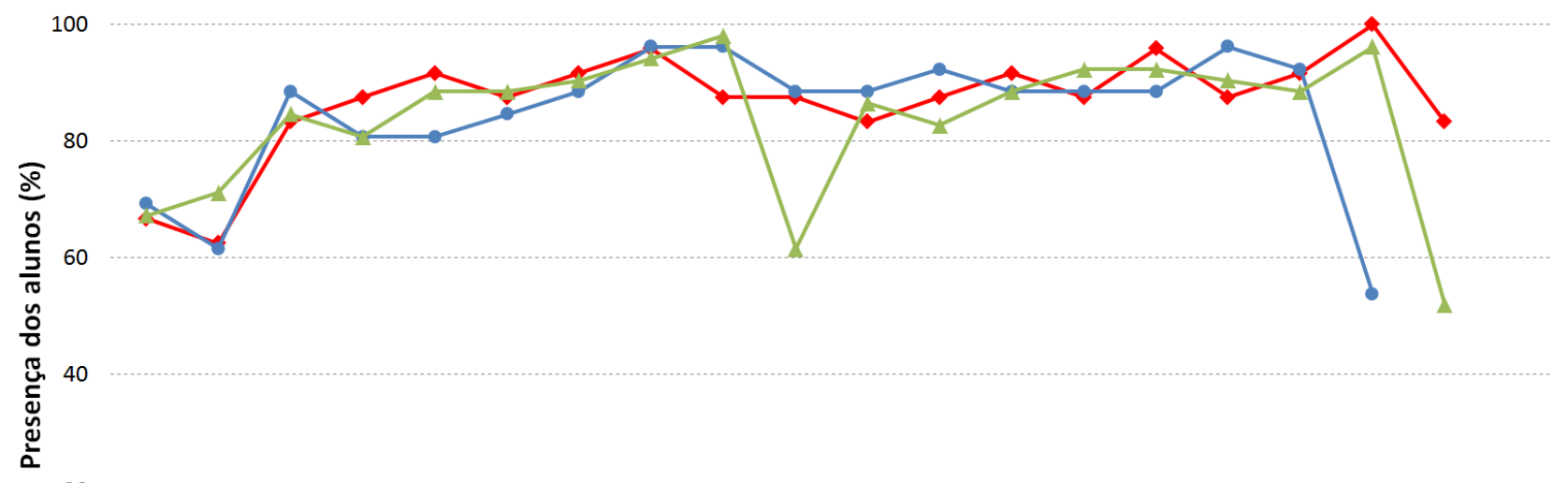

20

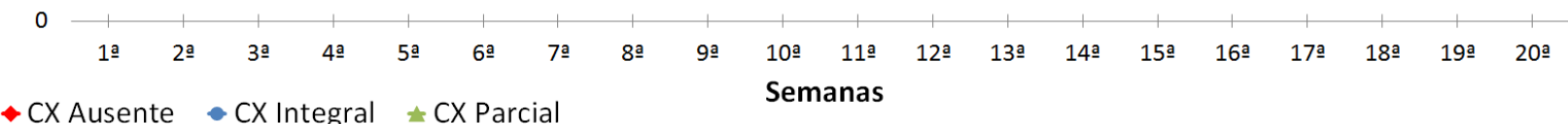

Figura 7: Frequência em turmas de pós-graduação que cursaram a disciplina A. 


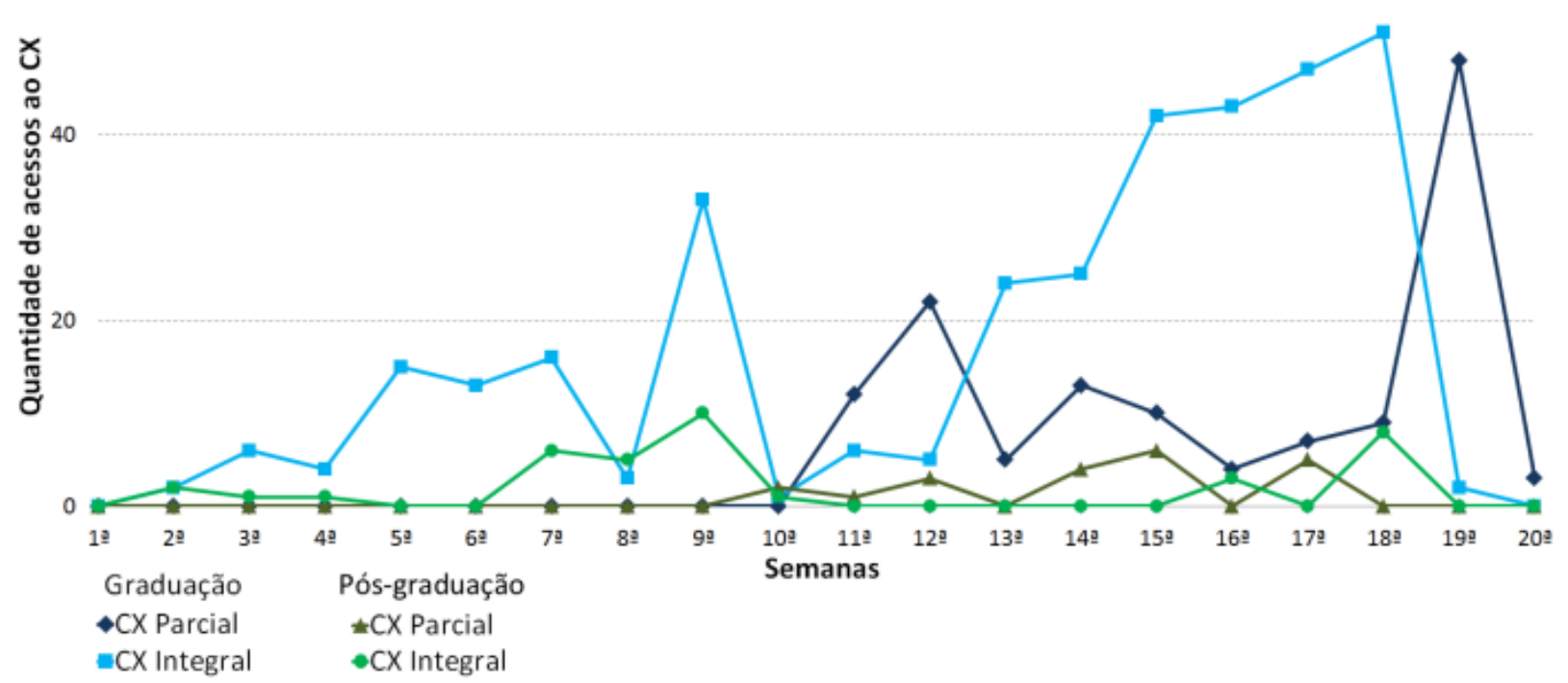

Figura 8: Quantidade de acessos ao Sistema por turmas de graduação e pós-graduação que cursaram a disciplina A.

Em contrapartida, na graduação observaram-se quantidades expressivas de acesso ao sistema no decorrer de todo o período observado. Nas primeiras semanas dos bimestres, os alunos se interessaram pela novidade e acessaram o CX para conhecer suas funcionalidades. Em seguida, os usuários permaneceram utilizando a ferramenta para estudarem os conteúdos capturados pelos professores durante as aulas e, nesses períodos, registrouse uma quantidade de acessos ininterrupta e bastante variável. Nas épocas de provas (nona, décima oitava e décima nona semanas), observaram-se picos de acesso ao sistema, pois os usuários realizaram a revisão da matéria utilizando o CX. Ao final dos bimestres, houve quedas gradativas no número de acessos, chegando a zero em todos os casos a partir da vigésima semana. Junto às turmas que cursaram a disciplina $\mathrm{A}$, também avaliaram-se as frequências de acesso das turmas das disciplinas $\mathrm{B}$ e C, percebendo-se resultados similares em ambas.

Ainda com relação à frequência de acessos realizados ao sistema, também observou-se quais foram os motivos que mais levaram os alunos a acessarem a interface Web do CX e a partir de quais locais originaram-se essas visitas. Nas Figuras 9 e 10, são ilustradas as informações dadas pelos alunos nos momentos em que acessaram o sistema e responderam a um mini formulário no qual, a cada visita, eram requeridas informações contextuais sobre como eles se encontravam naquela circunstância.

É possível observar nos círculos menores à esquerda que em 33\% das visitas o mini formulário de contexto de acesso foi ignorado. Tal fato se explica pelos alunos que acessaram o CX cotidianamente simplesmente terem fatigado-se de o preencherem a cada visita e optarem por não respondê-lo. Entre as respostas válidas, a maioria dos

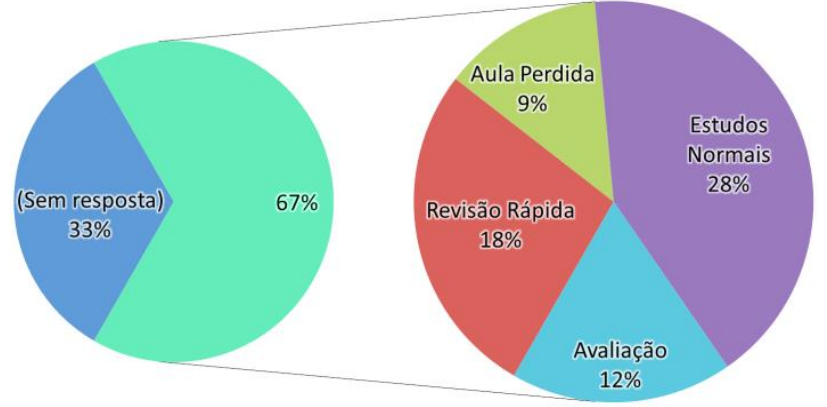

Figura 9: Motivos dos alunos terem acessado o sistema durante os semestres avaliados.

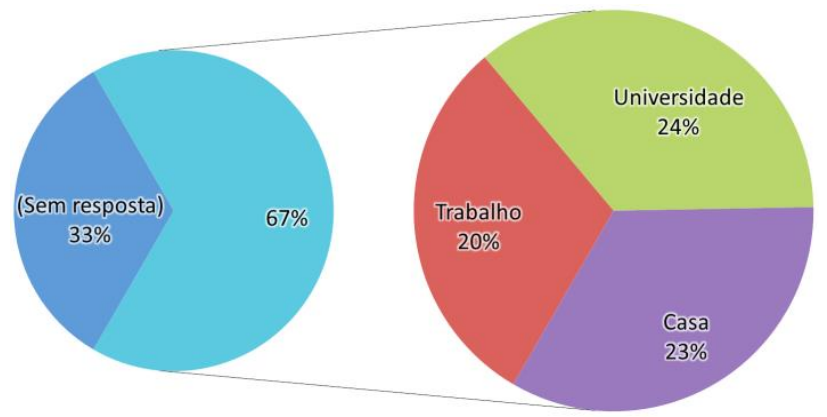

Figura 10: Locais de onde originaram-se os acessos ao sistema durante os semestres avaliados.

alunos acessou o sistema para estudar normalmente enquanto estavam presentes na universidade, algo inesperado pois supunha-se que a taxa de acesso originada da instituição seria baixa, ao passo que mais visitas seriam realizadas a partir das casas dos alunos.

Percebeu-se, também, que os discentes utilizaram bastante o CX para revisões rápidas de conteúdo e estudos 
para avaliações, com o intuito de apurar seus conhecimentos sobre determinada matéria. Entretanto, em períodos próximos às provas, quando houve picos de acesso ao sistema, os usuários apresentaram tendência a ignorar o mini formulário de contexto, o que parcialmente contradiz os dados ilustrados nos gráficos. Em razão disso, acredita-se que os dados obtidos por meio do mini formulário sofreram enviesamento, já que os demais parâmetros contextuais - aferidos automaticamente - mostraram-se de acordo com o modo que os acessos ao sistema aconteceram e diferiram-se apenas dos dados informados manualmente. Isso leva à necessidade de se automatizar a maneira que essas informações são coletadas, para que elas não se oponham às demais e nem sejam perdidas devido à displicência que os usuários têm de informar repetidamente esses parâmetros a cada acesso.

\subsection{Impressões}

Questionários foram utilizados para se identificar e analisar as impressões que alunos tiveram sobre o $\mathrm{CX}$. Dentre os 214 discentes que utilizaram o sistema, 117 deram suas impressões. Com o objetivo de minimizar respostas mal intencionadas, fez-se o uso de técnicas de legitimação de respostas utilizando tanto a negação de alternativas [12] quanto limites inferiores temporais [18].

Os questionários foram compostos por uma lista de 18 afirmativas sucedidas por duas questões nas quais os discentes deveriam informar os motivos que mais os levaram a utilizar o $\mathrm{CX}$ e suas críticas e sugestões sobre o sistema. As afirmativas utilizadas nesses questionários são listadas a seguir:

1. Eu recomendaria o CX e gostaria de utilizá-lo com mais frequência.

2. O uso do CX não aumentou meu interesse pelas aulas da disciplina.

3. As funcionalidades e informações do CX estão bem integradas e organizadas.

4. Achei difícil utilizar o CX.

5. $\mathrm{O}$ uso do $\mathrm{CX}$ pelo professor me estimulou a ir às aulas e estudar mais.

6. Para se fazer qualquer coisa no CX são necessários muitos passos.

7. É agradável visualizar as aulas que foram gravadas pelo $\mathrm{CX}$.

8. Mesmo com as aulas sendo gravadas, ainda anoto tudo o que o professor diz.

9. No CX as mensagens de erro e ajuda são adequadas.
10. Achei o CX muito complicado e não o indicaria para meus colegas.

11. O CX me permitiu prestar mais atenção nas aulas e explicações do professor.

12. As informações e atividades estão desorganizadas no CX.

13. Eu me senti confiante usando o CX.

14. Nem sinto mais vontade de assistir às aulas presencialmente, pois elas são gravadas.

15. A maioria das pessoas pode aprender a usar o CX rapidamente.

16. Eu acho que há inconsistências no CX.

17. Eu gostei do modo que as aulas são gravadas e o conteúdo é apresentado.

18. Achei o CX frustrante de se usar.

Após o período de aplicação dos questionários, um limite inferior temporal de dois minutos e trinta segundos foi empregado para analisar as 117 respostas obtidas e percebeu-se que em 11 delas o tempo gasto para respondê-las estava abaixo do limite. Esse limite foi determinado preliminarmente, por meio da aplicação do mesmo questionário (sem a questão de críticas e sugestões) para um grupo reduzido de estudantes. O limite inferior foi obtido ao se calcular a média de tempo gasto pelos indivíduos e arredondá-la para baixo, resultando num período mínimo para usuários responderem corretamente às questões. Por haver maior possibilidade das respostas abaixo deste tempo terem sido informadas de maneira mal intencionada, optou-se por removê-las da análise final da pesquisa. Na Figura 11, é possível observar a proporção de alunos matriculados em cada curso que compuseram as respostas válidas dos questionários aplicados.

Posteriormente, utilizou-se a métrica de negação de alternativas sobre os tópicos que tratavam da mesma ideia de maneira aparentemente oposta. As afirmativas utilizadas para este fim foram, respectivamente, 1 e 10 (que versaram sobre a frequência de uso do sistema e sua recomendação para colegas), 2 e 11 (sobre o nível de interesse nas aulas em que os professores utilizaram o $\mathrm{CX}$ ), 3 e 12 (relativas à organização das informações presentes nas telas da interface), 4 e 13 (acerca da facilidade e confiança de se usar o sistema) e 5 e 14 (sobre os alunos sentirem-se estimulados a frequentarem as aulas).



Figura 11: Proporção dos cursos frequentados pelos discentes que responderam ao questionário. 
Em cada par de itens, esperava-se que os alunos respondessem com opiniões distintas, dado que em cada um deles havia tanto ideias de descontentamento quanto afirmações positivas a respeito do mesmo tema. Para verificar as afirmações opostas, realizou-se a inversão do segundo item de cada par e calcularam-se os resultados obtidos de maneira conjunta, com o intuito de evidenciar ou anular as respostas dadas no primeiro item. Os resultados obtidos após a aplicação dessas técnicas de legitimação podem ser observados na Figura 12, que apresenta os níveis de concordância dos alunos com relação às afirmativas respondidas e os motivos que mais os levaram a acessar o sistema.

A maioria dos alunos não apresentou dificuldades em utilizar o CX e informou que recomendaria seu uso para os colegas, demonstrando também interesse em utilizá-lo com mais frequência. As funcionalidades do sistema e mensagens de erro/ajuda presentes na interface foram consideradas organizadas e bem integradas por grande parte dos discentes, que sentiram-se confiantes ao utilizar o sistema. Esse contingente também informou que prestou mais atenção nas explicações dos professores que faziam uso do sistema durante as aulas, declarando que a gravação dos conteúdos não os desestimulou a assistirem

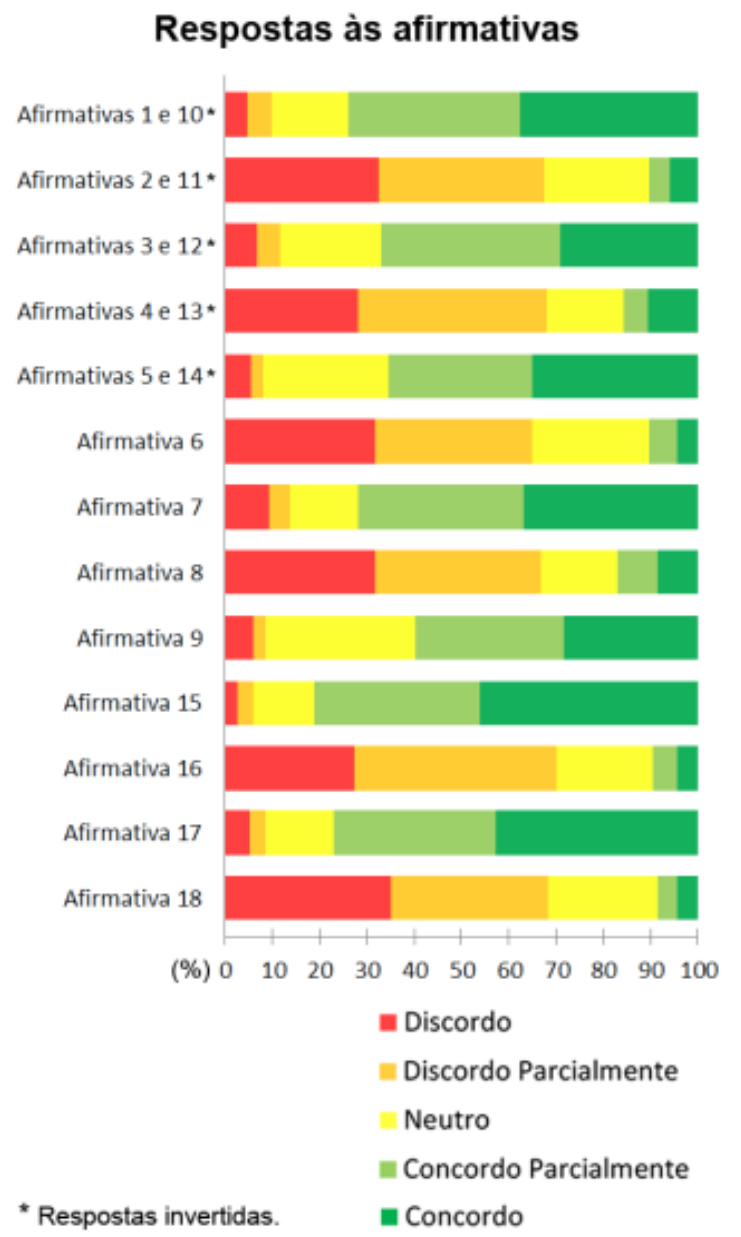

presencialmente as disciplinas e até incentivou-os a estudarem mais determinados conteúdos. Grande parte dos alunos informou que a maioria das pessoas pode aprender a usar o sistema rapidamente, declarando, também, que gostaram do modo que as aulas foram gravadas e não consideraram o CX frustrante de se utilizar.

Sobre os motivos que mais levaram os discentes a acessarem o sistema, 46,2\% das respostas associaram seu uso a estudos para as avaliações. Essa informação confirma os dados anteriormente obtidos na Figura 8, em que picos de acesso ao sistema foram observados em épocas próximas às provas bimestrais, mas diverge da Figura 9, na qual o maior objetivo observado foi referente a estudos normais, seguido por revisões de conteúdo. Embora os $\operatorname{logs}$ de contexto de acesso possuam os dados de todas as visitas que o sistema recebeu no decorrer dos semestres observados (e essa quantidade pode ter sido composta por mais acessos ordinários), os resultados obtidos utilizando-se meios que foram legitimados se mostram mais fiéis às demais vertentes que foram analisadas. Portanto, acredita-se que o maior motivo de uso do CX foi com relação a estudos que alunos realizaram para se preparar para as provas das disciplinas.

\section{Motivos de terem utilizado o CX:}

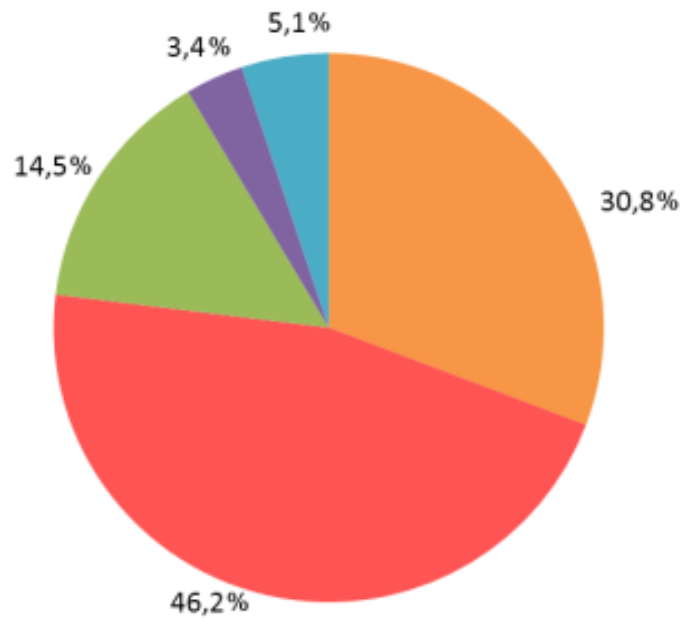

Estudos normais/revisões

Estudar para avaliações

Estudar o conteúdo das aulas que faltei

- Outros

(Sem resposta)

Figura 12: Nível de concordância dos alunos com relação às afirmativas dos questionários e motivos que os levaram a acessar o CX. 
A respeito das críticas e sugestões coletadas em uma pergunta aberta contida nos questionários, entende-se que a proposta geral do sistema foi de encontro a opiniões manifestadas. Um aluno respondeu "Achei legal porque prestei mais atenção na aula e não precisei ficar copiando", enquanto outro complementou que "É muito no sentido de revisar o que o professor deu na aula, pois podemos voltar quantas vezes forem necessárias e revisar algo que ele tenha dito/escrito na sala". As críticas mais frequentes observadas entre alunos disseram respeito à possibilidade de se fazer o download do conteúdo gravado em um único arquivo e a indisponibilidade que o $\mathrm{CX}$ apresentou durante alguns períodos. A respeito do download de arquivos capturados, uma funcionalidade para este fim se encontra em desenvolvimento pela equipe. Com relação à indisponibilidade que o sistema apresentou, tal problema ocorre devido a própria rede da universidade na qual a pesquisa foi realizada apresentar eventuais instabilidades que estão além do alcance dos pesquisadores envolvidos na investigação. Outra carência a ser suprida diz respeito à refinação das mensagens de estado do CX, atentando-se para circunstâncias em que as aulas gravadas são sincronizadas com o servidor. Além disso, um período maior inicial para treinamento dos professores provavelmente necessite de mais atenção, junto ao desenvolvimento de material didático sobre como se utilizar o sistema.

\section{Trabalhos Relacionados}

A aplicabilidade da área de C\&A tem se fortalecido na literatura tanto por meio de trabalhos mais extensos e abrangentes $[16,22,25,30]$ quanto por pesquisas mais específicas que estudam o uso dessas aplicações em contextos exclusivos, como em locais de trabalho [10, 21, 27], circunstâncias cotidianas [2, 9, 15] e ambientes educacionais $[1,6,8,23]$. Por isso, realizar investigações a respeito das vantagens e desvantagens do uso dessas aplicações é uma atividade relevante e atual, capaz de averiguar aspectos e obter informações para tornar essas experiências cada vez melhores para os usuários.

No âmbito acadêmico, as aplicações de C\&A são um tema de pesquisa frequente, já que possibilitam a criação de Ambientes Educacionais Ubíquos (AEUs) e automatizam os processos de ensino e aprendizagem gerando benefícios para usuários dentro e fora das salas de aula $[1,4,17]$. Na literatura, trabalhos que apresentam análises sobre a C\&A em âmbitos educacionais têm avaliado diversas particularidades dessas aplicações, como o processo de criação de infraestruturas que unificam dispositivos computacionais ubíquos [25] e a maneira que os usuários se comportam quando têm contato com tais ambientes [6]. Entre as investigações observadas, também é possível perceber objetivos de pesquisa que bus- cam responder a questões similares, evidenciando, em sua maioria, tanto fatores como a frequência e o desempenho de alunos [23, 29], quanto a disposição, impressões e experiências de professores $[5,20]$.

Dentre os trabalhos analisados, a maioria se mostrou voltada para a avaliação de estudantes de graduação [6, 24, 29]. Isso se justifica pelas investigações nessa área precisarem considerar as diferentes particularidades dos indivíduos, como seus níveis de escolaridade e estilos de aprendizagem, atentando-se para fatores que demonstram as nuances que os métodos educacionais possuem em lugares diferentes. $\mathrm{Na}$ presente pesquisa, analisaram-se tanto discentes de graduação quanto de pós-graduação e melhores resultados foram percebidos entre graduandos a pós-graduandos. Tal fato se mostra como um indicativo de que determinada faixa de discentes apresenta mais receptividade à inserção de novas tecnologias educacionais e o nível de escolaridade dos usuários tende a ser um fator de peso para refinar investigações na área.

$\mathrm{Na}$ literatura, o questionário foi a técnica de avaliação mais utilizada entre os trabalhos relacionados $[5,6,23$, 24]. Nesses estudos, os usuários que tiveram contato com os AEUs normalmente informaram suas impressões sobre as tecnologias e deram críticas e sugestões de novas funcionalidades para engrandecer os sistemas. Todavia, nos trabalhos em que a análise de dados baseou-se apenas nesse tipo de resposta, foi possível perceber que não houve métodos de validação regulares, o que acabou inibindo a correta verificação das informações e, eventualmente, gerou conclusões pretensiosas e refutáveis.

Em Settle et al. [23], por exemplo, fez-se o uso de questionários para avaliar as impressões de alunos, mas não se aplicou técnicas para legitimar essas respostas. Ao se analisar o respaldo dos usuários, percebeu-se que a maioria demonstrou satisfação em acessar o sistema e que haviam compreendido melhor o conteúdo - o que naturalmente ocasionaria em rendimentos melhores. Em seguida, com o intuito de relacionar os resultados, empregaram-se técnicas estatísticas para analisar se os usuários que interagiram com o AEU realmente obtiveram notas melhores que os demais, mas ao final da etapa descobriuse que não houve diferença significativa entre as turmas observadas. $\mathrm{O}$ trabalho então concluiu-se de maneira confusa, explicando que não foi possível afirmar que a tecnologia resultou em benefícios pois os dados se mostraram contraditórios. Todavia, percebe-se que a investigação falhou no método de pesquisa empregado, já que apenas parte das informações foi corretamente validada.

No trabalho de Euzent et al. [7] também examinou-se o rendimento de diferentes turmas que assistiram à mesma disciplina, atentando-se para o emprego do mesmo professor e método de avaliação. Numa das turmas utilizou-se uma nova abordagem de captura de aulas no se- 
mestre letivo, enquanto na outra as aulas foram lecionadas de modo clássico. $\mathrm{O}$ intuito do trabalho foi compreender se a gravação dessas aulas causava algum tipo de dano à maneira que o conteúdo era repassado aos alunos e se a aprendizagem seria prejudicada de algum modo. Ao final da pesquisa, mesmo com os dados sendo corretamente legitimados, não se observou diferença expressiva entre as notas finais das turmas, mas percebeu-se que a faixa de rendimento do segundo bimestre foi maior na turma que utilizou o sistema, o que permitiu a conclusão de não ter havido danos ou prejuízos para os alunos, mas tampouco ganhos significativos.

Neste trabalho, objetivou-se validar não apenas os resultados obtidos durante a análise do desempenho dos alunos, mas também as respostas informadas nos questionários aplicados. Deste modo, compreendeu-se que o maior ganho aconteceu entre alunos de graduação, pois crescimentos significativos nas notas apareceram entre quase todas as turmas que utilizaram o sistema integralmente e entre todas as que fizeram seu uso parcial. Essa informação foi ao encontro das respostas obtidas nos questionários, em que alunos informaram que o uso do CX foi capaz de aumentar seus interesses pelas aulas e estimulou-os a estudar mais os conteúdos. Tais resultados demonstram que, além do respaldo favorável relativo ao uso da tecnologia educacional entre graduandos, as técnicas empregadas nesta pesquisa se mostraram planejadas de maneira correta.

Sobre a assiduidade dos discentes, no trabalho de Preston et al. [19] concluiu-se que as tecnologias educacionais não causam quedas na presença de alunos, mas que a própria frequência em sala de aula tem decaído como um todo nos últimos anos. Conforme Gysbers et al. [11], aplicações educacionais têm sido injustamente acusadas de provocarem a inassiduidade de alunos, tendo na verdade procurado modificar a maneira que as aulas são ministradas para atrair discentes desmotivados.

Nesta pesquisa, as frequências de turmas que não tiveram contato com o sistema não apresentaram diferenças expressivas daquelas que usaram o CX parcial ou integralmente. Observou-se que houve fluxos de assiduidade específicos em cada turma, mas nada que fugisse da frequência esperada em semestre letivos habituais. De certo modo, maiores variações aconteceram nas presenças de alunos de graduação que não usaram o sistema, algo também observado nas demais turmas, mas em menor intensidade (Figura 6). Entretanto, esse fato não aconteceu entre alunos de pós-graduação, que mantiveram altas taxas de assiduidade durante todos os semestres observados (Figura 7).

Com relação à intensidade que os usuários acessam aplicações educacionais, em Dickson et al. [6] analisaram-se as frequências de acesso de alunos em cursos de graduação e pós-graduação, com o intuito de se compreender quando e como as aulas gravadas haviam sido utilizadas no cotidiano. Ao se validar e comparar os dados obtidos, percebeu-se que os discentes de pósgraduação utilizaram a tecnologia bem mais que os de graduação. Com isso, concluiu-se que a maturidade e o comprometimento dos estudantes tendeu a progredir à maneira que eles se aprofundaram na área acadêmica.

No presente trabalho, também analisou-se a quantidade de acessos realizados ao sistema por turmas de graduação e pós-graduação, todavia, o resultado se mostrou oposto ao de Dickson et al. [6]. Enquanto as turmas de graduação apresentaram taxas de acesso contínuas no decorrer das semanas, mantendo-se geralmente progressivas até as épocas de prova; na pós-graduação o nível de acessos se mostrou bastante reduzido (Figura 8). Além disso, turmas de graduação que utilizaram o sistema de modo integral durante os semestres o acessaram bem mais no segundo bimestre, período em que acredita-se que os discentes indicaram o CX para seus colegas, contribuindo para o crescimento do número de acessos. Entretanto, é importante frisar que a quantidade de alunos avaliados na graduação e na pós-graduação foi diferente, sendo expressivamente maior entre os graduandos. Esse fator certamente pesou na quantidade de acessos realizados por cada tipo de discente, o que abre margem para que uma análise mais profunda sobre alunos de pósgraduação seja realizada para que questões desse âmbito sejam melhor esclarecidas.

\section{Considerações Finais}

Esta pesquisa objetivou analisar os benefícios e obstáculos que o emprego de uma nova tecnologia computacional ubíqua é capaz de propiciar a ambientes reais de ULearning. Com base na análise dos resultados obtidos, percebeu-se que o uso parcial e integral do CX trouxe aumentos de desempenho para a maioria das turmas de graduação observadas durante a pesquisa. Esta elevação demonstra que o uso do sistema foi capaz de influenciar o rendimento dos alunos de graduação que fizeram seu uso no cotidiano, pois houve um aumento significativo na média das notas desses estudantes e uma diminuição no desvio padrão resultante. Na pós-graduação, apenas uma das turmas obteve elevações expressivas na média dos desempenhos. No entanto, foi justamente numa turma de pós-graduação que observou-se a maior queda do desvio padrão dentre todas as turmas analisadas, resultando numa redução de $32,7 \%$ para $14,8 \%$ da variação do desempenho dessa turma e garantindo o maior nivelamento observado nesta pesquisa entre os pós-graduandos.

Com base nesses resultados, acredita-se que a plataforma CX obteve uma utilização mais eficiente entre 
alunos de graduação que na pós-graduação. Especula-se que os pós-graduandos já possuem seus próprios métodos de estudo e tendem a ser mais esforçados - o que faz com que seus níveis de desempenho e assiduidade sejam naturalmente elevados com ou sem a utilização de novas tecnologias educacionais. De modo a reforçar ainda mais esses resultados, acredita-se que seja interessante realizar uma análise do perfil de conhecimento prévio dos alunos estudados. Com essas informações, será possível identificar a existência de estudantes que já tiveram contato com as temáticas abordadas nas disciplinas e diferenciá-los daqueles que não as viram anteriormente.

Com relação à assiduidade, a frequência dos alunos de graduação não sofreu mudanças expressivas entre as turmas que tiveram ou não contato com o sistema no decorrer dos semestres analisados. No entanto, variações constantes e abruptas na presença em sala de aula dos graduandos foram mais visíveis nas turmas que não utilizaram o CX do que naquelas em que o sistema foi empregado. Na pós-graduação, o uso do sistema não apresentou qualquer reflexo de modificação na frequência das turmas, que mantiveram-se com níveis de assiduidade acima de $80 \%$ na maior parte das semanas observadas. Além disso, quedas de assiduidade que sucederam épocas de provas (nos períodos em que houve correções de avaliações e disponibilização de notas) foram observadas em todas as turmas investigadas, mas mostraram-se menores entre os discentes da pós-graduação.

A respeito do nível de acesso ao sistema, turmas de graduação empregaram o CX bem mais que os alunos de pós-graduação. Todavia, em $33 \%$ das vezes que os usuários visitaram o $\mathrm{CX}$, optaram por ignorar o mini formulário de contexto que, dentre outros dados, requeria informações sobre a origem e motivo dos acessos. Acredita-se que os alunos que acessaram o sistema cotidianamente simplesmente fatigaram-se de ter de preencher o mini formulário a cada visita e optaram por ignorá-lo, enviesando os dados obtidos por este meio. Por isso, automatizar o aferimento do contexto de acesso mostra-se como uma funcionalidade que precisa ser urgentemente implementada para que o índice de respostas não seja contraditório e nem perdido em pesquisas futuras, de modo que novas análises sobre o contexto em que os alunos se encontram ao acessar o CX possam ser realizadas e permitam a obtenção de dados fiéis e conclusivos.

Por fim, com base nas impressões de usuários coletadas empregando-se questionários, foi possível perceber que o uso do sistema foi bem aceito de maneira geral. $\mathrm{O}$ feedback positivo dado pelos alunos permitiu compreender que o processo de captura das aulas mostrou-se adequado para os estudantes. Como os questionários empregados tiveram suas respostas validadas, julga-se prudente confiar nos resultados que foram obtidos por este meio. Cerca de $70 \%$ dos discentes que responderam ao questio- nário frequentavam cursos de graduação, o que fez com que as respostas obtidas mantivessem uma proporção semelhante à quantidade de graduandos e pós-graduandos avaliados no decorrer da pesquisa. Os alunos em sua maioria gostaram da plataforma CX e fizeram seu uso de maneira cotidiana para estudar os conteúdos capturados pelos docentes. Alguns pontos de melhoria foram levantados, como instabilidades durante finais de semana e a possibilidade de se fazer o download dos slides das aulas. No entanto, os alunos demonstraram interesse em utilizar frequentemente o CX durante semestres letivos e informaram que recomendariam a aplicação para seus colegas, de modo a aumentar ainda mais a quantidade de usuários em contato com a aplicação.

\section{Referências}

[1] Z. Aihua. Study of Ubiquitous Learning Environment Based on Ubiquitous Computing. Em Proc. of the $3^{\text {rd }}$ IEEE UMEDIA. Págs. 136-138, 2010.

[2] M. Al-Mutawa, S. Mishra. System Support for Anywhere Anytime Personal Computing Environment. Em Proc. of the $2^{\text {nd }} M-P A C$. Págs. 1-5, 2010 .

[3] R. D. Araújo, T. Brant-Ribeiro, R. G. Cattelan, S. A. de Amo, H. N. Ferreira. Personalization of Interactive Digital Media in Ubiquitous Educational Environments. Em Proc. of the IEEE SMC’13. Págs. 3955-3960, 2013.

[4] D. J. Cook, S. K. Das. Pervasive Computting at Scale: Transforming the State of the Art. Pervasive and Mobile Computing. 8(1):22-35, 2012.

[5] J. Danielson, V. Preast, H. Bender, L. Hassall. Is the Effectiveness of Lecture Capture Related to Teaching Approach or Content Type? Computers \& Education. 72(0)121-131, 2014.

[6] P. E. Dickson, D. I. Warshow, A. C. Goebel, C. C. Roache, W. R. Adrion. Student Reactions to Classroom Lecture Capture. In Proc. of the 17th ITiCSE. Págs. 144-149, 2012.

[7] P. J. Euzent, T. L. Martin, P. Moskal, P. Moskal. Teaching Principles to the Masses: Assessing Student Performance in Lecture Capture vs. Face-to-Face Course Delivery, 2011. http://ssrn. com/abstract=1868945. Acesso em Maio/2015.

[8] H. N. Ferreira, R. D. Araújo, S. de Amo, R. G. Cattelan. Classroom Experience: A Platform for Multimedia Capture and Access in Instrumented Educational Environments. Em Proc. of the SBSC'12. Págs. 59-64, 2012. 
[9] R. Gouveia, E. Karapanos. Footprint Tracker: Supporting Diary studies with Lifelogging. Em Proc. of the CHI'13. Págs. 2921-2930, 2013.

[10] R. Gumienny, L. Gericke, M. Quasthoff, C. Willems, C. Meinel. Tele-board: Enabling Efficient Collaboration in Digital Design Spaces. Em Proc. of the $15^{\text {th }}$ CSCWD. Págs. 47-54, 2011.

[11] V. Gysbers, J. Johnston, D. Hancock, G. Denyer. Why do Students Still Bother Coming to Lectures, When Everything is Available Online? International Journal of Innovation in Science and Mathematics Education. 19(2)20-36, 2011.

[12] J. L. Huang, P. G. Curran, J. Keeney, E. M. Poposki, R. P DeShon. Detecting and Deterring Insufficient Effort Responding to Surveys. Journal of Business and Psychology. 27(1)1-16, 2012.

[13] Internet World Stats. World Internet User Statistics and World Population Stats, 2014. http://www.internetworldstats.com/stats.htm.

Acesso em Maio/2015.

[14] International Telecommunication Union. Percentage of Individuals Using the Internet, 2014. http://www.itu.int/en/ITU-D/Statistics/Document s/statistics/2014/Individuals_Internet_2000-2013 .xls. Acesso em Maio/2015.

[15] M. Kay, E. K. Choe, J. Shepherd, B. Greenstein, N. Watson, S. Consolvo, J. A. Kientz. Lullaby: A Capture \& Access System for Understanding the Sleep Environment. Em Proc. of the UbiComp'12. Págs. 226-234, 2012.

[16] J. A. Kientz. Embedded Capture and Access: Encouraging Recording and Reviewing of Data in the Caregiving Domain. Personal and Ubiquitous Computing. 16(2)209-221, 2012.

[17] Kinshuk, S. Graf. Ubiquitous Learning. Em Encyclopedia of the Sciences of Learning. Págs. 3361-3363, 2012.

[18] A. W. Meade, S. B. Craig. Identifying Careless Responses in Survey Data. Psychological Methods. 17(1)437-455, 2012.

[19] G. Preston, R. Phillips, M. Gosper, M. McNeill, K. Woo, D. Green. Web-Based Lecture Technologies: Highlighting the Changing Nature of Teaching and Learning. Australasian Journal of Educational Technology. 26(6):717-728, 2010.

[20] V. I. Prodanov. In-Class Lecture Recording: What Lecture Capture has to Offer to the Instructor. Em Proc. of the ASEE PSW'12. 12 págs., 2012.
[21] S. Renals. Recognition and Understanding of Meetings. Em Proc. of the $11^{\text {th }}$ NAACL. Págs. 19, 2010

[22] A. Schmidt, B. Peging, C. Holz, L. E. Holmquist. From Photography to Ubiquitous Capture Systems. Pervasive Computing. 13(1) 10-13, 2014.

[23] A. Settle, L. Dettori, M. J. Davidson. Does Lecture Capture Make a Difference for Students in Traditional Classrooms. Em Proc. of the $16^{\text {th }}$ ITiCSE. Págs. 78-82, 2011.

[24] E. Smyth, J. Volker. Enhancing Instruction with Visual Media: Utilizing Video and Lecture Capture. IGI Global. Harrisburg, PA, 2011.

[25] K. N. Truong, G. R. Hayes. Ubiquitous Computing for Capture and Access. Foundations and Trends in Human-Computer Interaction. 2(2) 95-171, 2009.

[26] K. N. Truong, G. Abowd, J. Brotherton. Who, What, When, Where, How: Design Issues of Capture \& Access Applications. Em Proc. of the $3^{\text {rd }}$ UbiComp. Págs. 209-224, 2001.

[27] D. A. Vega-Oliveros, D. S. Martins, M. d. G. C. Pimentel. Media-oriented Operators for Authoring Interactive Multimedia Documents Generated from Capture Sessions. Em Proc. of the 2011 ACM SAC. Págs. 1267-1272, 2011.

[28] M. Weiser. The Computer for the $21^{\text {st }}$ Century. Scientific American. 265(3)66-75, 1991.

[29] M. B. Wieling, W. H. A. Hofman. The Impact of Online Video Lecture Recordings and Automated Feedback on Student Performance. Computers \& Education. 54(4)992-998, 2010.

[30] Z. Yu, Y. Nakamura. Smart Meeting Systems: a Survey of State-of-the-art and Open Issues. $A C M$ Computing Surveys. 42(2)1-20, 2010.

[31] X. Zhao, X. Wan, T. Okamoto. Adaptive Content Delivery in Ubiquitous Learning Environment. Em Proc. of the $6^{\text {th }}$ WMUTE. Págs. 19-26, 2010.

[32] S.-L. Wang, C.-Y. Wu. Application of ContextAware and Personalized Recommendation to Implement an Adaptive Ubiquitous Learning System. Expert Systems with Applications. 38(9)10831-10838, 2011. 